\title{
Associations between demographic factors and perceived acculturative stress among African migrants in Germany
}

\author{
Erhabor Sunday IDEMUDIA \\ School of Research and Postgraduate Studies, Faculty of Human and Social Sciences, North-West \\ University (Mafikeng Campus), South Africa. erhabor.idemudia@nwu.ac.za
}

\begin{abstract}
This study investigated the nature and extent of the associations between demographic variables and acculturative stress of African migrants in Germany with the premise that living in Germany would be stressful for Africans. Data from 85 migrants from the general population and prisons showed that $73.4 \%$ were males and $26.6 \%$ females with age ranging from 18 to 46 years. Participants completed the MAQ used in assessing acculturative stress.

Results from hierarchical regression analysis showed that: majority of Africans reported racial discrimination, negative situation, a precarious job and a huge volume of daily hassles as predominant problems experienced in Germany. Acculturative stress increased with duration of stay in Germany. Family fragmentation and being separated from one's spouse was a strong predictor of acculturative stress. Being an economic refugee was also associated with acculturative stress. Recommendations were made in the light of the conclusions made in the study.
\end{abstract}

Keywords: African migrants; Demographic factors; Germany; Migration; Psychology; Stress

\section{Résumé}

L'hypothèse est que la vie est stressante pour les émigres Africains en Allemagne, cette étude a évalué le dégrée d'association entre les données démographiques et le stress d'acculturation des émigrés africains en Allemagne. Les données ont été collectées sur une population des 85 émigrés dans la vie courante et quelques prisonniers parmi lesquels, $73.4 \%$ étaient des hommes et $26.6 \%$ des femmes avec l'âge variant entre 18 à 46 ans. Les participants ont accompli le MAQ test utilisé pour évaluer le stress d'acculturation. Les résultats de l'analyse de rétrogradation hiérarchique ont montré que la majorité de ces émigres ont été sujet d'un énorme volume de complications quotidiennes entre autres la discrimination raciale, la vie difficile, un emploi précaire. Le stress d'acculturation augmente avec la durée de séjour en Allemagne. La dispersion familiale surtout d'être sépare de son conjoint était parmi le plus grand factor de stimulation de stress d'acculturation. Être un réfugié économique a été aussi associé au stress d'acculturation. Les recommandations ont été faites sur base des conclusions faites dans cette étude.

Mots clé: émigres africains; facteurs démographique; Allemagne; Migration; Psychologie; Stress

\section{Introduction}

Many youths (particularly those from the East, Central, North and western) parts of Africa) believe that traveling to Europe and other western countries would put an end to their problem thinking that it is all bed of roses: lands flowing with milk and honey. According to Adepoju (20II), distorted information on labour market conditions in EU countries, increasing professionalism of traffickers, scams and bogus travel intermediaries have been cited as fuelling the numbers and especially the desperation of these youths. As a result, they travel in droves using unsafe means such as trolleys, dinghies and cargo ships and some do trek through the valleys and shadows of death of the hot Sahara desert. In the process, many of them die resulting in world headlines. Those who succeed, on arrival find that the land that was supposed to flow with milk and honey actually flow with hardships, police harassments, racism, imprisonment, daily 
apprehension of deportation and other hosts of hostile life situations. To keep 'body and soul' together, some of them engages in drug distribution, prostitution, domestic thefts and therefore end in prisons while some engage in petty and menial jobs such as dish washing in restaurants, street cleaning, corpse cleaning, etc. It is not uncommon to find university graduates doing menial jobs in Europe. Germany should not be a normal destination for Africans because German language is not what Africans readily speak due to lack of colonial ties such as English (UK, USA, Canada) or French (France, Canada). The premise of the study therefore, is anchored on the hypothesis that living in Germany would be stressful for Africans as indeed they are what is often termed 'aliens' in legal migration lingo: Visible outsiders in a cultural context. The purpose of this paper therefore, is to understand if there is a relationship between demographic characteristics of migrants and their perception of acculturative stress in Germany.

\section{Literature Review:}

Unfortunately, studies linking demographic variables with acculturative stress are scarce and particularly for African migrants. Berry (1997) considers the acculturative experience as a major life event that is likely to be influenced by both societal composition and individual level variables. Society of origin, group acculturation, and society of settlement, and various individual variables are strong factors affecting acculturation experience and level of stress. According to Ward, Bochner and Furnham (200I), intercultural contact and change occurs in a sociopolitical and economic context which can be influenced by the characteristics of the migrant's society of origin and society of settlement and as such the changes associated with this contact are viewed as precipitating stress which results in affective, behavioural and cognitive coping responses. The Similarity-Attraction hypothesis (Byrne, 1969) also presupposes that stereotypes will occur when people differ markedly from each other on idiosyncratic characteristics because relationships and interactions will be based on social categorisation, which consequently can lead to racial discrimination. According to Fernando, (1993), racism is the most serious risk factor for immigrants. Other researchers (Ataca, 1996; Furhnham and Shiekh, 1993; Vega, Gil, Warheit, Zimmerman and Apospori, 1993 and Ward and Chang, 1994) have also found negative correlates of perceived discriminations or prejudice and psychological well-being. Tanaka, Takai, Kohyama, and Fujihara (1994) and Ward and Searle, (1991) have also argued that attitudes held by members of the dominant culture strongly influence patterns of immigrants adaptation. However, research has shown a general satisfaction of new lives and better wellbeing among sojourners and immigrants with low education (Idemudia \& Boehnke, 2005, 2006, 2010).

Ward et al (200I) have argued that values, as evaluative beliefs are cognitive constructs, which are tied to self-definition. In other words, when men see things, as real then it will real in behaviour. One measure of how effective or helpless a person feels is the trait dimension of optimism and pessimism, manifested by positive thinking. This is the individual's expectation of a good outcome of an event, or negative thinking; that is, the tendency to expect misfortune or the worst outcome of an event. Psychologists in this school measure the reciprocal influences between people and their situations and how these situations are perceived and the level of control over those situations using questionnaires and observing people's behaviour in a particular situation. They draw conclusions from self-report and direct observation of the behaviours. However, the association between demographic variables and perceptions of acculturative stress is hardly understood in migration studies. The aim of this paper therefore, is to understand how demographic variables are associated with acculturative stress among African migrants in Germany.

\section{Theoretical Perspectives:}

Social identification theories (e.g. Ward et al., 200I) posit that shared values can promote positive attitudes towards out-group members. The similarity-attraction hypothesis (Byrne, 1969) predicts that individuals are more likely to seek out, enjoy, understand, want to work and play with, trust, believe, vote for, and generally prefer people with whom they share salient characteristics. By definition, cross-cultural interactions occur between individuals who are likely to be discordant (Babiker, Cox, \& Miller, 1980). According to Ward, et al. (200I) the culture-distance hypothesis predicts that the greater the cultural gap between people in contact, the more difficulties they will experience. A social categorization process is engaged to classify others as members of own in-group, or to some other outgroup (Abrams \& Hogg, 1990). This form of categorization of people has consequences for how 
people so categorized are perceived and treated by the in-group (Tajfel, 1970, 198I), with in-group members given preference (Bochner \& Cairns, 1976). Negative stereotyping of immigrants could result (Katz \& Braly, 1933; Lippmann, 1922).

\section{Data Sources and Method:}

\section{Design}

The study is a cross-sectional study which sampled participants using the snowballing method for collecting data because of the sensitive nature of the research, particularly among those who were illegally residing in Germany as the author was viewed by many participants as a 'government agent' and as such were reluctant to be part of the study. Structured questionnaires were sent to participant's addresses by post and were returned via same in prepaid envelopes to eliminate ability to identify respondents.

\section{Sample:}

The sample consists of migrants in the general population and those in prisons. Both samples were merged for an overall data and reported as such. However, for the purpose of clarity and details, both samples are compared. Altogether, data were collected from 85 African migrants living in Germany, 62 from the general population, 23 from the prison population. Of the 85 participants, $26.6 \%$ are women and $73.4 \%$ men with age ranging from 18 to 46 years. Marital status showed $38.1 \%$ are single, $34.6 \%$ are either separated or divorced, and $27.4 \%$ are married. Educational attainments are as follows: Some $9.2 \%$ have only primary or no education while one half of the participants have a secondary education (or equivalent) while $14.5 \%$ of the participants have post-secondary education and $26.3 \%$ have completed at least a first university degree. The majority of respondents came from Nigeria (56.5 \%), Ghana (9.4\%), Senegal (4.7\%), Kenya, Congo (Kinshasa), and Togo (2.4\%, each) and about $13 \%$ came from other African countries, and about $9 \%$ refused to indicate their country. With regard to reasons for migration to Germany, $40.5 \%$ indicated economic problems at home, political problems (20.3\%), study (19.0\%), work (II.4\%), and family reunion (8.9\%). As for the number of years participants have stayed in Germany, answers ranged between half a year and 20 years. The mean length of stay/residence in Germany is $71 / 2$ years (SD $=41 / 2$ years). The participants include legal, illegal residents and those locked up in correctional (prison) settings as at the time of study. Temporary visitors were excluded from the study.

\section{Settings:}

Data were collected in the following cities: Bremen, Hamburg, Bonn, Frankfurt am Main, Düsseldorf, Köln (Cologne), Bayreuth, Stuttgart, Koblenz, Neustadt an der Weinstraße in the State of Rhineland-Palatinate, Berlin, Hannover, and München (Munich). For the prison population, authorities in 12 German states were contacted for possible permission to solicit respondents from prisons under the jurisdiction of their state. Only Bavaria, Berlin, Bremen, Hessen, Mecklenburg-Western Pomerania, and Schleswig-Holstein responded positively, in principle, on the ministerial level. It usually took an average of about 2-3 months to get a response from the justice ministry and prison authorities. Many of the prison participants also were afraid of the motive of the study despite several clarifications made to them. In addition, few - if any-African inmates were available in prisons that gave permission at the time of the study. There also was a constant movement of prisoners around prisons in Germany. The return rate of questionnaires was, however, very low; only about II \% of the questionnaires were returned. However, Holbrook, Krosnick, and Pfent (2007) have shown that there is no systematic relationship between response rates and the size of bias encountered in surveys.

\section{Instruments and psychometric properties:}

Migration Attitude Questionnaire (MAQ): The Migrant Attitude Questionnaire was developed by the author and used to measure general perceived attitude concerning experiences in a new country. It is a 20 -item questionnaire and it is used as a self-rated questionnaire. Each question has five possible responses: Not at all (0), very little (I), Sometimes (2), Most of the time (3) and All of the time (4).

Reliability and Validity: The scale was pretested with 3I African migrants from the general population in Bremen to establish the consistency and validity of the Migration Attitude Questionnaire (MAQ). Items for the scale were generated from the migrants themselves. Migrants were asked to write down list of stressors which were then factor analysed (discussed elsewhere). In the pre-test the internal consistency of the scale (with appropriately reversed items) was high (overall alpha and standardized item 
alpha both were .86). This indicates that the MAQ is highly reliable for use among African migrants. The Migration Attitude Questionnaire was derived from reports on daily experiences of African migrants themselves, items were retained in the language used by migrants (see Table I). The MAQ was used to measure acculturative stress.

\section{Table I}

\section{Items of the Migration Attitude Questionnaire}

\# Wording of Item

I I have been wasting away since I arrived here

2 Compared to before, economically my situation has improved

3 I enjoy an improved living standard

4 The cohesion of my family is good

5 I experienced police harassment

6 I have felt racial discrimination

7 I sense prejudice from Germans

8 I have been confronted with prejudice from fellow Africans

9 I feel socially backward

10 Living here is very stressful

II I am happier than before

12 I am very sad

13 I want to go back home

14 I have no decent job

I5 I am going through a lot of hassles

16 I want to live here forever

17 I am confused

18 I regretted having come here

19 I admire equal opportunities to job and health care

20 I am confronted with so many problems

\section{RESULTS: Demographic Characteristics}

Gender: In the overall sample, there were 26.6 $\%$ women and $73.4 \%$ men. Tested by a binomial test the proportions differ significantly $(p<.00 \mathrm{I})$.
Among 'the participants from the general population, there were $34.5 \%$ women and $65.5 \%$ men. In the prison subsample, all but one were men (95.2\%).

Age: The mean age of the full sample is 31.65 with a standard deviation of 7.3I. In 2008 the average age of legal African residents of Germany is reported to be 34. I, likely to have increased slightly from the time the survey was conducted ${ }^{1}$.

Marital Status: In the overall sample 38.1 \% were single, $34.6 \%$ were either separated or divorced, and $27.4 \%$ were married. In the general population sample $35.5 \%$ were single, $42.0 \%$ were separated or divorced, and only $22.6 \%$ were married. This results of analyses of the sociodemographic data makes it necessary-and interesting-to take a special look at differences in acculturative stress according to marital status.

Educational and Professional Attainment: Current levels of educational attainment are as follows in the grand sample: Some $9.2 \%$ have only primary or no education, down from $10.5 \%$ upon arrival to Germany. Exactly one half of the participants have a secondary education (or equivalent), down from $56.6 \%$ upon arrival. At least some post-secondary education have $14.5 \%$, up from $11.8 \%$ upon arrival, whereas $26.3 \%$ have completed at least a first university degree) up from $21.1 \%$. Differences in educational attainment between the general population sample and the inmate sample were significant; Wilcoxon's $W$ was significant $(p=.048)$ : educational attainment was lower in the inmate subsample.

Occupation statuses of participants showed that $12.9 \%$ of all participants were students at the time of surveying, $18.8 \%$ had skilled professional occupations, a relative majority of $37.6 \%$ held skilled non-professional jobs, $11.8 \%$ were employed in unskilled jobs, whereas $18.8 \%$ of the respondents were unemployed. Also here the sample seems to be fairly representative for the population of African migrants residing in Germany. More detailed data for African migrants in Germany could not be obtained, so that one has to take the overall data for migrants as a point of reference. Between participants from the general population distributions of professional attainment differ significantly $(\mathrm{p}<.00 \mathrm{I})$ from those in prisons, (Figure I). Relative proportions and absolute

\footnotetext{
${ }^{1}$ https://www-

ec.destatis.de/csp/shop/sfg/bpm.html.cms.cBroker.cls?cmspath=struktu r,vollanzeige.csp\&ID= 1015274
} 
frequencies of the different occupations in the two subsamples are documented in Figure I.

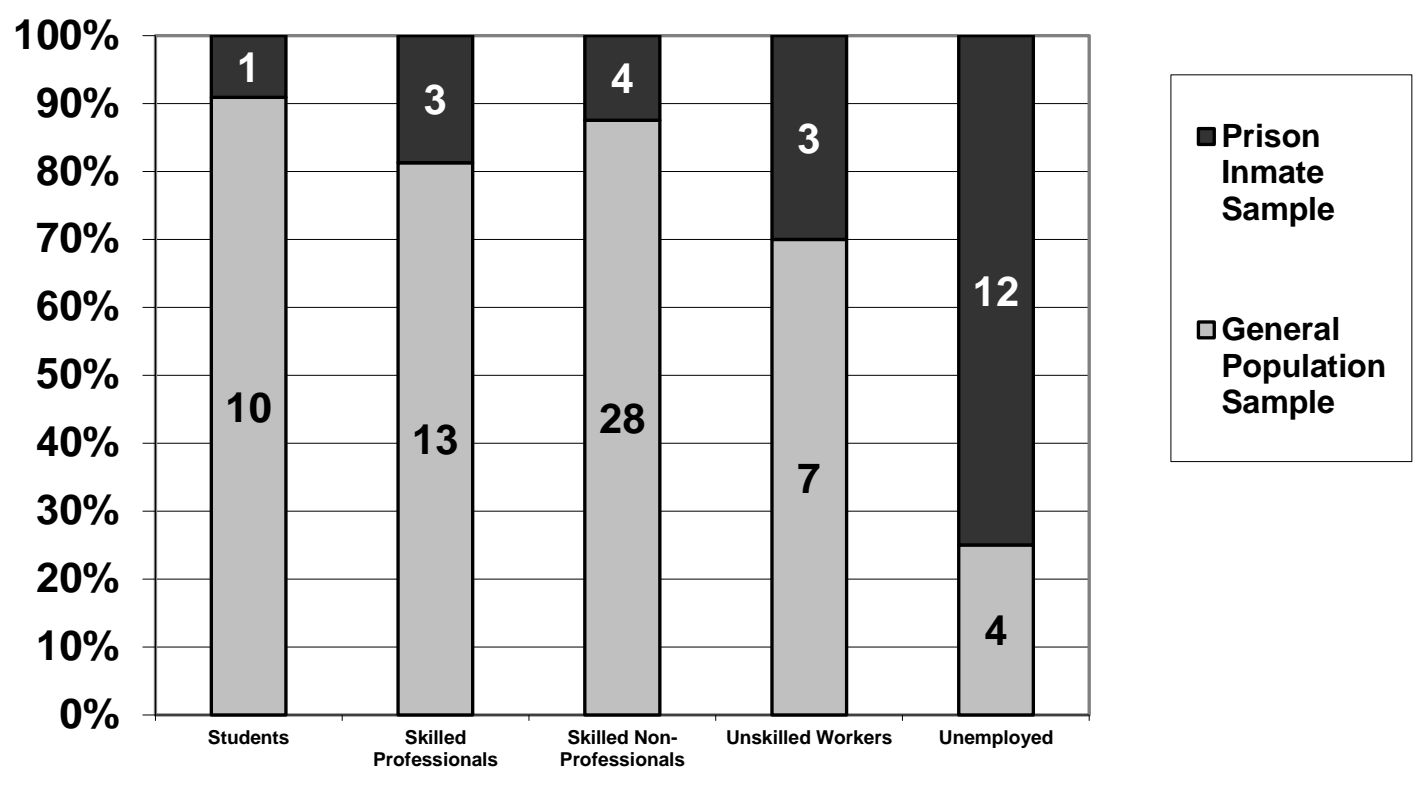

Figure I: $\quad$ Relative and Absolute Frequencies of Occupations of Respondents

Country of Upbringing, Migration Motivation, and Duration of Stay in Germany

The participants were also asked to indicate from where they migrated to Germany. Majority of respondents came from Nigeria (56.5\%). More than a single respondent was interviewed from Ghana (9.4 $\%)$, Senegal (4.7\%), Kenya, Congo (Kinshasa), and Togo (2.4\%, each). Some $13 \%$ came from other African countries, while more than $9 \%$ of the respondents refused to indicate their country of upbringing. If a study includes illegal immigrants from Africa, obtaining nationalities seems to be a 'tricky' issue. Considerable numbers of respondent were unwilling to disclose their country of upbringing during the anonymous survey.

As for reasons to migrate to Germany, $41 \%$ indicated economic problems at home as the main reason, $20.3 \%$ came for reasons of political problems at home, $19.0 \%$ came to study in Germany, II.4\% came to seek work (without indicating economic problems at home), and $8.9 \%$ came for family reasons (one or the other type of family reunion as the main reason).

As for the number of years participants have stayed in Germany, answers had a considerable range, varying between half a year and 20 years. The average duration of stay in Germany was 7.46 years with a standard deviation of $4.5 \mathrm{I}$ years.

\section{RESULTS: MAQ and demographic variables}

Table I gives means and standard deviations for the $20 \mathrm{MAQ}$ items in the order of descending means, i.e., from the item that drew highest approval to the one that drew least approval. The table shows that the most pressing problem of African immigrants to Germany is that they see themselves as having no decent job.

For further analyses an index variable was formed that is assumed to measure the overall degree of acculturative stress experienced by the surveyed immigrants. The development of this index variable was based on an exploratory factor analysis-details omitted here as they are discussed elsewhere. All those items that had its highest loadings on the strong first factor of the scale (eigenvalue 9.215) were averaged for the calculation of the index variable (after appropriate recoding if pertinent). Items I, 5, $6,7,9,10,12,13,14,15,17,18,19$ (reversed), and 20 were used to form the index variable (Table 2 )

The index variable had a mean of 2.39 with a standard deviation of I.I4. Consistency of the acculturative stress variable was very high; Cronbach's alpha was .95. 
Acculturative stress can reasonably be assumed to decrease in the course of a longer stay. It seems logical
Table 2

Means of the Migration Attitude Questionnaire

\begin{tabular}{|c|c|c|}
\hline Items (\#) & Mean & Standard Deviation \\
\hline No decent job (14) & 2.71 & 1.421 \\
\hline Lots of hassles (15) & 2.65 & 1.396 \\
\hline Economically improved (2) & 2.65 & 1.381 \\
\hline Very stressful life (10) & 2.65 & 1.363 \\
\hline Racial discrimination (6) & 2.65 & 1.395 \\
\hline Many problems (20) & 2.64 & 1.300 \\
\hline Improved living standard (3) & 2.60 & 1.063 \\
\hline Happier than before (II) & 2.58 & 1.380 \\
\hline Prejudice from Germans (7) & 2.38 & 1.385 \\
\hline Wasting away (I) & 2.35 & 1.685 \\
\hline Family cohesion (4) & 2.32 & 1.274 \\
\hline Very sad (12) & 2.23 & 1.515 \\
\hline Confused (17) & 2.15 & 1.527 \\
\hline Police harassment (5) & 2.11 & 1.637 \\
\hline Go back home (13) & 2.05 & 1.291 \\
\hline Regretted having come (18) & 2.03 & 1.566 \\
\hline Socially backward (9) & 1.97 & 1.581 \\
\hline Prejudice from Africans (8) & 1.36 & 1.135 \\
\hline Live here forever (16) & 1.34 & 1.259 \\
\hline Equal opportunities (19) & 1.16 & 1.332 \\
\hline
\end{tabular}

to assume that something like a culture shock should be strongest in the beginning of a migrant's stay in a new culture. For African immigrants to Germany, however, the opposite is true: The longer they stay in
Germany, the more acculturative stress they express. By correcting for a respondent's age, that is, correcting for the possibility that the older someone gets, the more stressed he or she feels, it can be 
shown that it is indeed the duration of stay that lets the experience of stress become stronger and not increasing age: A multiple regression analysis with degree of acculturative stress, emphasizes that it is the duration of stay $(B=.33, p=.014)$ and not the respondent's age $(B=.04, P=.779)$ that is significantly positively related to acculturative stress. It seems plausible to assume that the longer Africans stay in Germany, the more stressed they feel.

In subsequent analyses data was corrected for differences in both age and duration of stay, in order to obtain 'pure' results for the further effects that both duration of stay and age in years as predictors of the

were tested, but there were no results that might have their origin in difference in age and duration of stay.

As for marital status, distinct differences were found for the different status groups $(p<.01)$. It clearly emerged that divorced and separated respondents reported considerably higher acculturative stress than respondents who were either single or married. Figure 2 documents details.

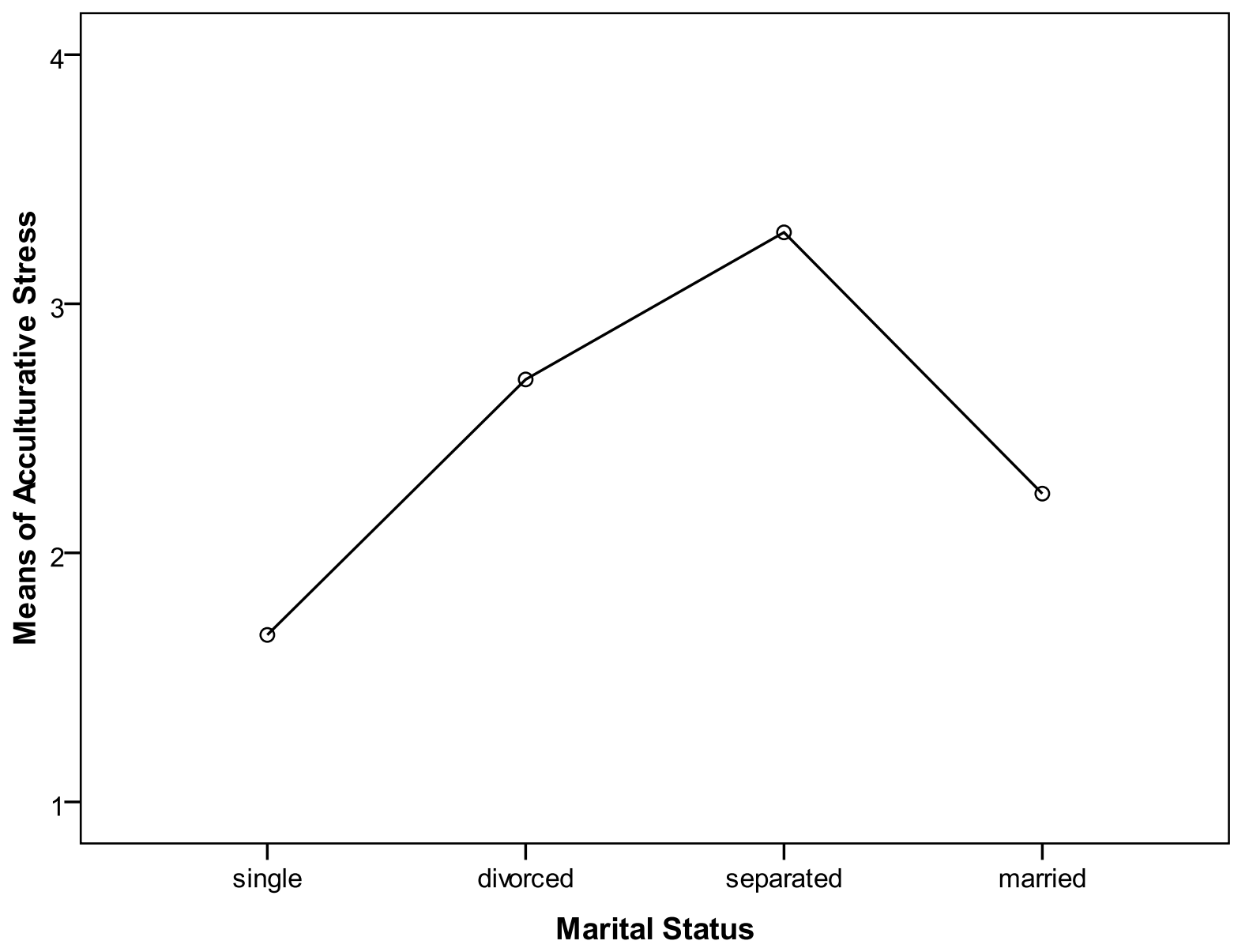

Figure 2 Acculturative Stress as a Function of Marital Status

The relationship between marital status and acculturative stress as documented in Figure 2, does, however, need amendment. If one checks whether the finding holds for both males and females, it emerges that divorced women, but separated men report the highest levels of acculturative stress. Divorced men, on the contrary, report lowest levels 455 of stress among all marital status groups $(\mathrm{p}<.00 \mathrm{I})$. Figure 3 reports details. Divorced men report a level of acculturative stress that makes them very similar to their single fellow migrants.

Figure 4 documents that men do not differ substantially according to their levels of educational attainment. Women with a secondary or equivalent 
level of education suffer most, while women with only primary or no education as well as women with a university degree report least acculturative stress. When looking at differences in acculturative stress according to present occupations, the ambiguous meaning of self-reported acculturative stress once again becomes obvious: Least stress is not surprisingly reported by students, but acculturative stress reported by unemployed African immigrants is almost identically low. Highest acculturative stress is reported by skilled non-professionals $(p=.003)$, probably the group that has the most genuine contact with locals. Figure 5 documents pertinent details

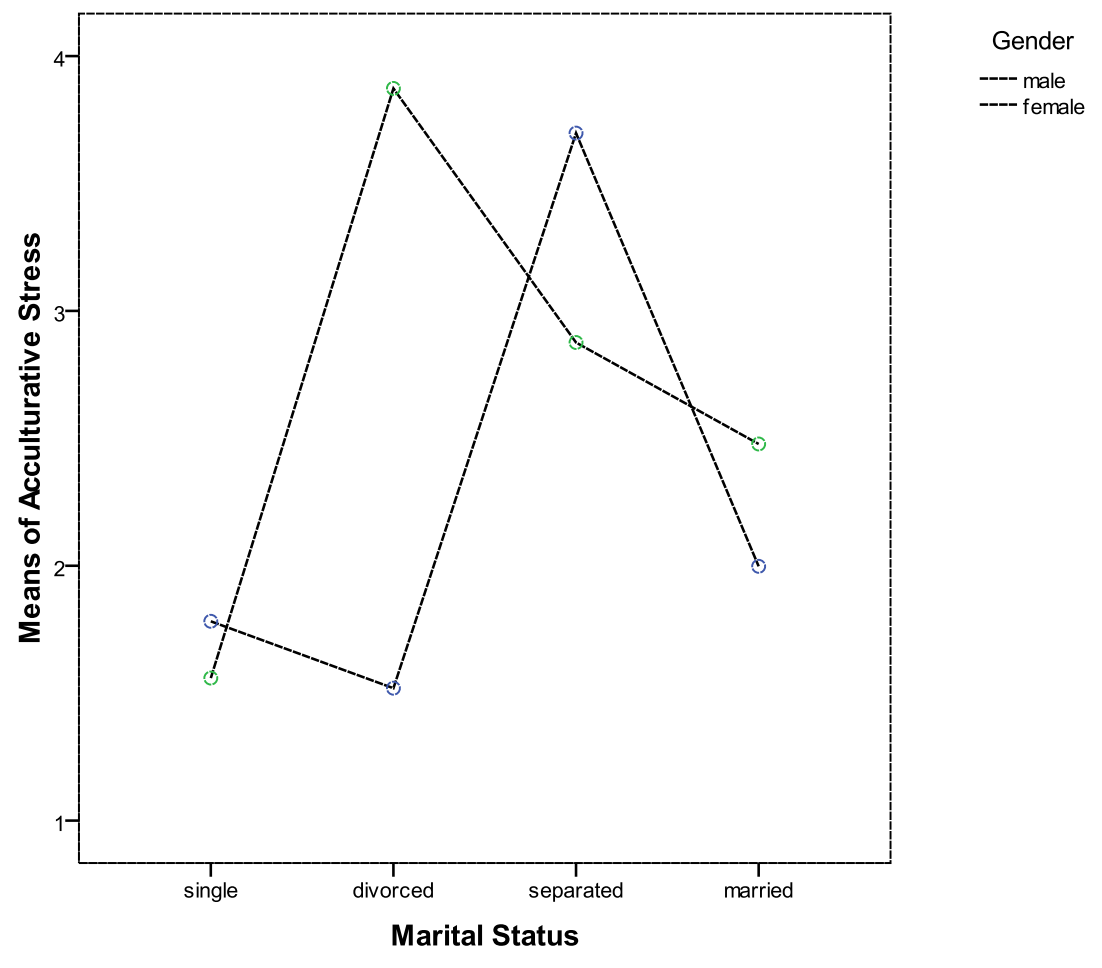

Figure 3 Acculturative Stress as a Function of Marital Status $\left(\% / \sigma^{\prime}\right)$ 


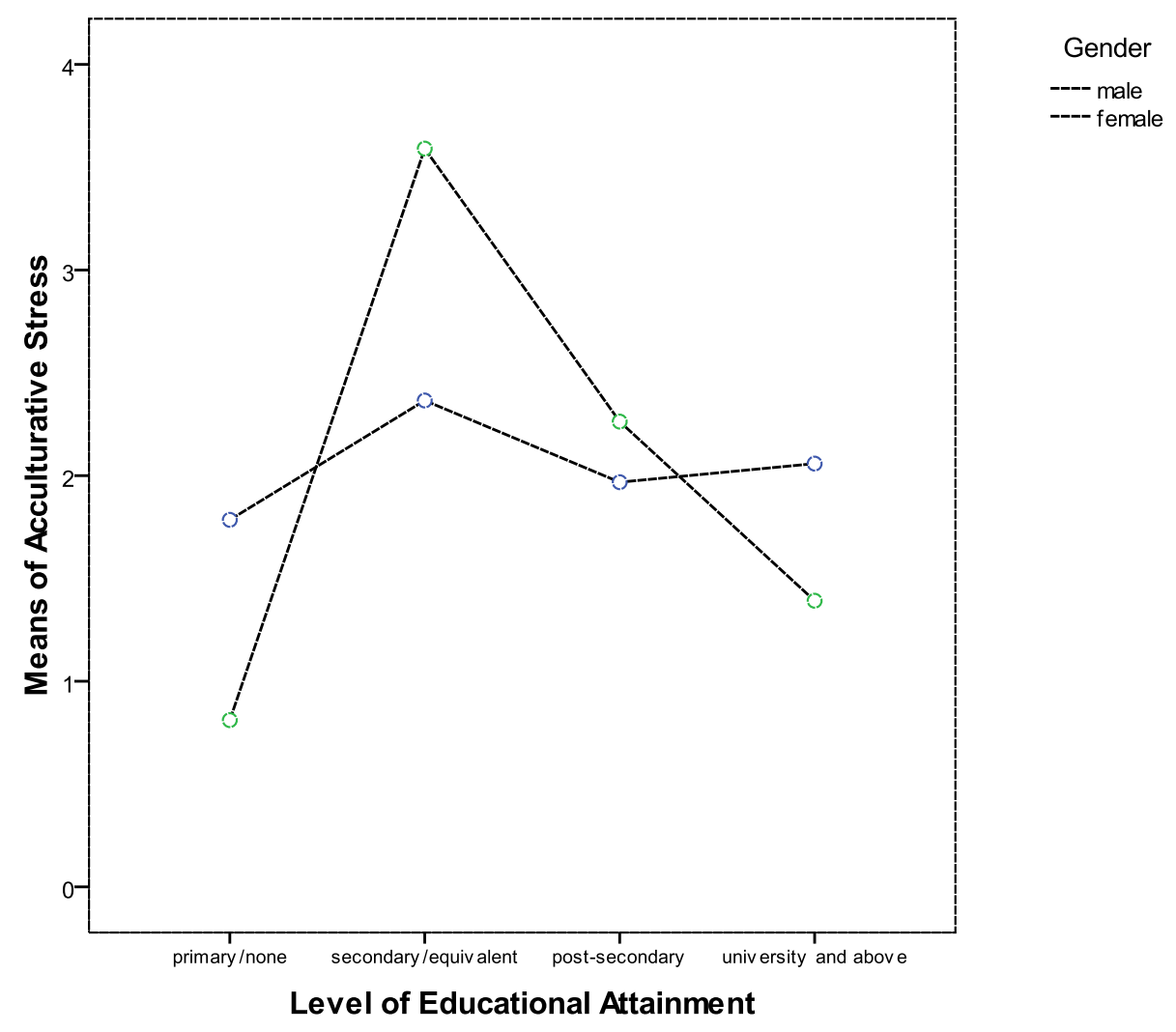

\section{Figure 4 Acculturative Stress as a Function of Educational Attainment $\left(\$ / \sigma^{\top}\right)$}

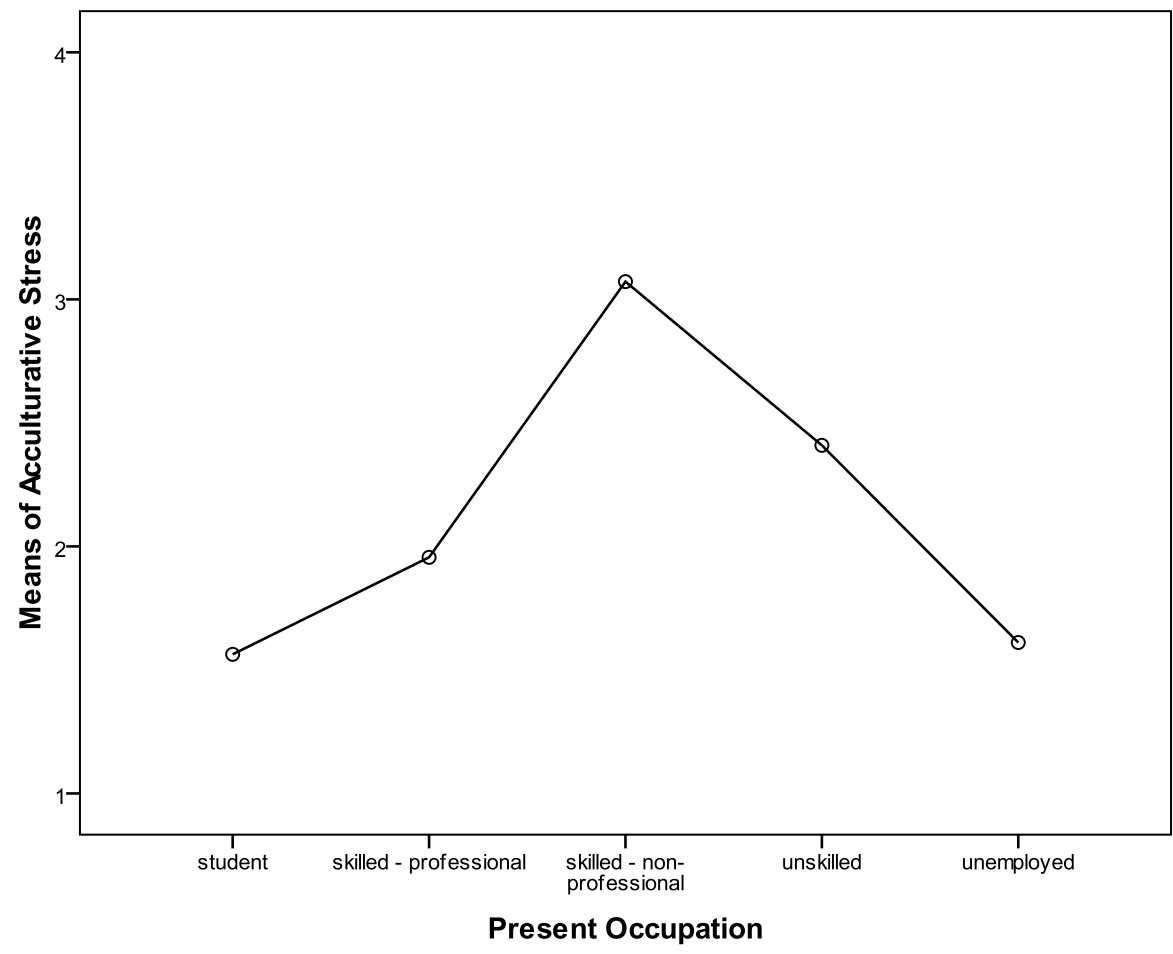

Figure $5 \quad$ Acculturative Stress as a Function of Present Occupation

Finally, differences in the migration motivation of African immigrants may have an impact on acculturative stress, and they indeed do $(p<.001)$. Figure 6 shows that having come to study, for political, or for family reasons goes along with relatively little acculturative stress, whereas having come for work or because of economic problems at home goes along with high acculturative stress.

In a concluding step, a hierarchic regression analysis was performed. In it all demographic 
variables included in the prior analyses of predictors of acculturative stress were entered into the regression equation in blocks. To accommodate for the relatively small sample size of the study, within blocks only variables that were at least marginally significantly related to the dependent variable 'acculturative stress' $(p<.10)$ were included, using the STEPWISE procedure. The analyses showed that $52.2 \%$ (adjusted R2) of the variance in acculturative stress is explained by the variables in the final equation. In substantive terms this means that more than one half of the acculturative stress of African migrants is explained by the variables tested in the analysis, most significantly as to whether migrants were separated $(B=.35, p=.001)$, came for reasons of economic problems at home $(B=.34, p$ $=.004)$, were divorced $(B=.29, p=.007)$, or came to seek work ( $B=.15, p=.093)$. When asked for an overall evaluation of their experience in Germany, $48.5 \%$ of all responses could be coded as 'negative,' $20 \%$ as 'neutral,' and $31.5 \%$ as 'positive.' When asked of what nature problems were that they had incurred in Germany, about one quarter of the respondents did not report any problems or explicitly indicated that they had never had any. On the other hand, a good third of the respondents reported problems with racial discrimination. The remaining 40 $\%$ of the respondents reported various other problems. When asked whether they had had problems with the law in Germany, $40 \%$ of all respondents indicated that they had had such problems, with $43.8 \%$ of them reporting criminal offenses as the reason for the problems. These data-from open questions-validate findings obtained with the acculturative stress measure: Acculturative stress and the overall assessment of the 'German experience' correlated significantly with each other. Kendall's $\square \mathrm{b}$ rank correlation was .37 ( $P$ $<.00 \mathrm{I}$ ). The correlation of acculturative stress and self-reported problems with racial discrimination was of a comparable size $(\square \mathrm{b}=.32, \mathrm{p}<.001)$. In a nutshell results of the analyses presented above can be summarized as showing that being separated from one's spouse and having come as an economic refugee are the most prominent sources of acculturative stress of African migrants in Germany. Having no decent job, being overburdened with hassles and problems, and racial discrimination by Germans are the most prominent sources of stress.

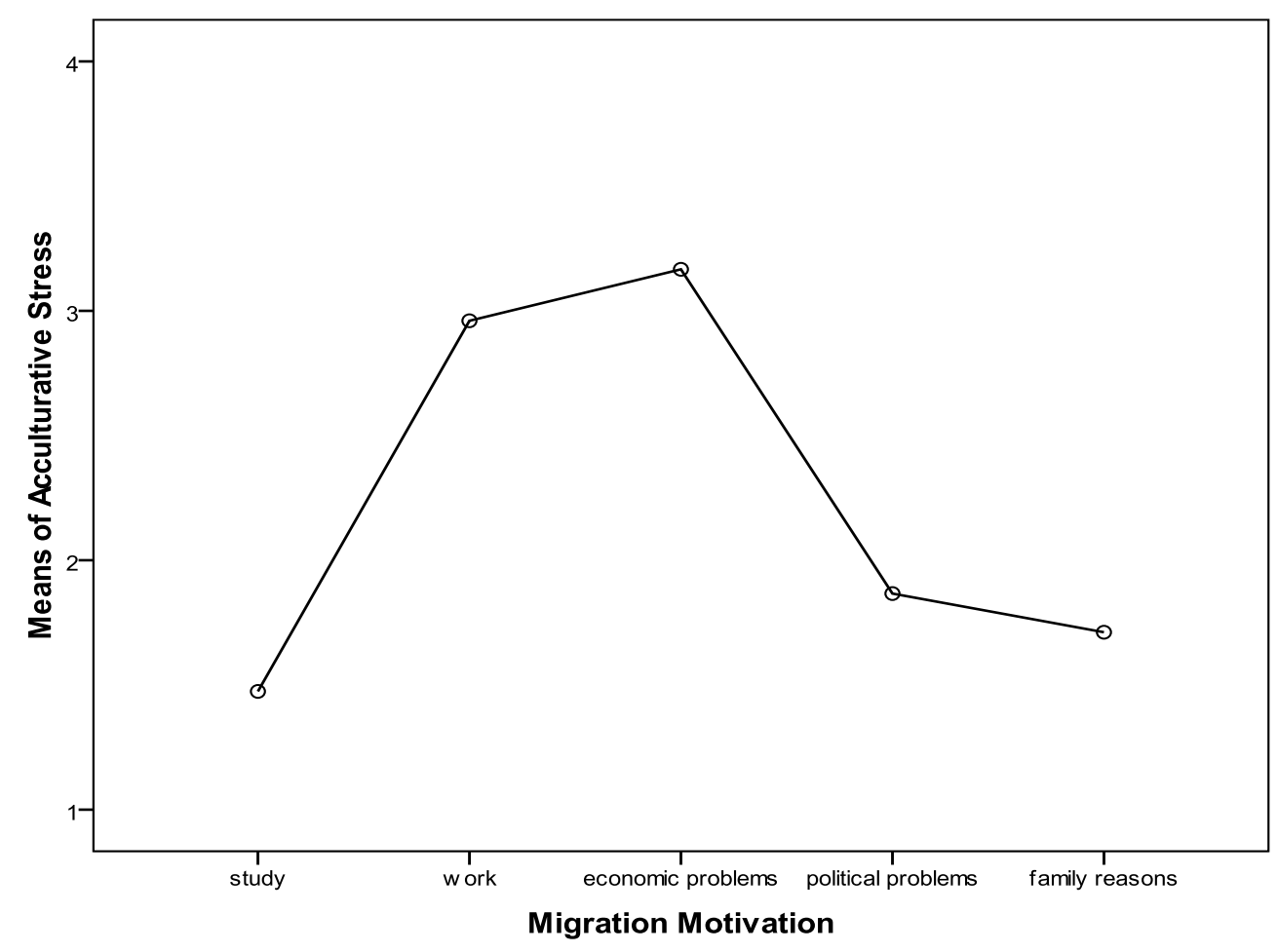

Figure $6 \quad$ Acculturative Stress as a Function of Migration Motivation

\section{Discussion and Conclusion:}

The aim of the research was to quantitatively provide data on the nature and extent of the associations between demographic variables (gender, age, marital status, educational level, motives for migrations, length of stay) and acculturative stress of African migrants in Germany. Data from inmate and general population samples were computed for the 
study. The MAQ was used to assess acculturative stress in Germany. In spite of the fact that the sample is small in size, there is no indication that it differs in its composition from a sample that is representative in a more technical sense: All major demographic variables are reflected in adequate proportions in the sample. The premise of the study was anchored on the hypothesis that living in Germany would be stressful for Africans more so as German language is not what Africans readily speak like English (UK, USA, Canada) or French (France, Canada). In Germany, they are indeed what is often termed 'aliens' in legal migration lingo: Visible outsiders in a cultural context that is generally not prepared for them.

According to data from the German Federal Office of Statistics, the percentage of females among legal African residents of Germany in the year of study (2003) was $36.9 \%$. In the present sample from the general population the percentage was just slightly lower, but considering the facts that considerable numbers of illegal immigrants were also included, who presumably are in the vast majority males, suggests that the gender proportions of the general population subsample are representative for Africans in Germany. The fact that in the prison subsample there are only 4.8 percent women also comes very close to being representative for the actual gender distribution of prison inmates. In 2006, $5.3 \%$ of all German prison inmates were women Given that the African population has fewer women to begin with, $4.8 \%$ perfectly matches the expected figure.

From the results of the study, Once again it can be assumed that the average age of the current sample is representative for Africans living in Germany, regardless of their legal status, because it seems plausible to assume that illegal immigrants are of a somewhat younger age, so that the average age of 31.7 reflects the typical age of African immigrants to Germany very well.

On Marital status, an assessment as to whether the percentages are representative for Africans residing in Germany is difficult. Data for the end of 2008 suggest that $46.0 \%$ of African legal residents of Germany were single, $40.0 \%$ were married, $6.7 \%$ were divorced, $1.0 \%$ were widowed and $6.3 \%$ were of unknown marital status. First of all, the situation may have changed slightly between the year of the survey and 2013, but no sufficiently exact data could be obtained for 2003. Secondly, no 459 comparative data is available for illegal immigrants, and thirdly it is difficult to determine, how people who in our survey indicated that they were separated would formally have been categorized in the official statistic.

However, there are significant differences in the duration of stay in Germany ( $p=.00 \mathrm{I}$ ) according to level of educational attainment: Immigrants with only primary or no education have stayed in Germany for a shorter time. Also are there significant differences in duration of stay between the different occupational groups ( $\mathrm{p}=.003$ ), with students and unskilled workers having stayed for a shorter period of time. There are marginally significant differences $(p=.065)$ according to migration motivation in duration of stay, migrants who have come to study having stayed for the shortest, migrants who have come because of economic problems at home having stayed for the longest period of time.

The educational status of the sample seems to be fairly representative for the population of African migrants residing in Germany. More detailed data for African migrants in Germany could not be obtained, so that one has to take the overall data for migrants as a point of reference.

Results of the MAQ showed that acculturative stress can reasonably be assumed to decrease in the course of a longer stay. It seems logical to assume that something like a culture shock should be strongest in the beginning of a migrant's stay in a new culture. For African immigrants to Germany, however, the opposite is true: The longer they stay in Germany, the more acculturative stress they express.

A further possible source of variation in acculturative stress is one's level of educational attainment. It is difficult to predict whether people with higher levels of education will express more acculturative stress or people with lower levels. Life will typically tend to be 'harder' for people with low levels of educational attainment. Acculturative stress, however, has a strong perceptual component, suggesting that also people with higher levels of education may after all experience more stress, because they are, on the one hand, more differentiated in their perception and, on the other hand, may be more easily disappointed about their factual accomplishments given their higher levels of education.

In a nutshell results of the analyses presented above can be summarized as showing that being separated from one's spouse and having come as an 
economic refugee are the most prominent sources of acculturative stress of African migrants in Germany. Having no decent job, being overburdened with hassles and problems, and racial discrimination by Germans are the most prominent sources of stress.

Acculturative stress arises predominantly from the inability to find a decent job, but also from the mere volume of daily hassles, and-not to forget-from the racial discrimination African migrants experience in Germany. While respondents reported some level of economic improvement, but many also indicated they would want to leave. Their life circumstances are far from satisfactory in absolute terms, but the fact that they are economically improved compared to where they come from motivates them to stay. This situation has features of a double bind: If a migrant seeks a radical solution to his or her problematic situation in Germany, looking for a new migration destiny or even returning to Africa may appear as a good idea. Putting this idea into reality would then, however, typically encompass a major deterioration of one's economic situation. The knowledge that this would be the case more or less instantaneously clearly negates the option to leave the problematic situation in Germany: The African migrant finds him or herself in a vicious circle. The present study does offer empirical evidence that Africans in Germany indeed experience this vicious circle: Their self-reported acculturative stress increases with the years of stay in Germany instead of decreasing with the longer adjustment time.

The described vicious circle is even intensified by the fact that those migrants who came to Germany for predominantly economic reasons, i.e., those often derogatively labelled economic refugees, are the ones who are worse off. They experience the relatively highest degrees of racism and increased levels of acculturative stress, but at the same time they are the ones who have no realistic option to return to their home countries or move on to a new migration destiny.

In general terms, the results of the present study supports Fernando's (1993) study which claimed that racism is the most serious risk factor for African immigrants to Western countries. Tanaka, Takai, Kohyama, and Fujihara (1994) as well as Ward and Searle, (199I) have argued in more general terms that attitudes held by members of the dominant culture strongly influence patterns of immigrant adaptation. Attitudes and values prevalent in the host society also serve as a frame for acculturation strategies of immigrants.

The stress-and-coping framework (Ward, Bochner, \& Furnham, 200I) assumes that because the experience of intercultural contact and change occurs in a socio-political and economic context and is influenced by the characteristics of the migrant's society of origin and society of settlement, changes associated with inter-culture contact are precipitating stress which results in affective, behavioural and cognitive coping responses. The Similarity-Attraction Hypothesis (Byrne, 1969) also presupposes that Africans and Germans are different on idiosyncratic characteristics, which will therefore lead to stereotypes (Social Categorization Theory) and consequently racial discrimination. This assumption does find some support in that racial discrimination indeed adds to acculturative stress.

The present study can be summarized as having corroborated the following facts:

- A majority of Africans in Germany reported their present situation in Germany as being negative.

- Racial discrimination, a precarious job, a huge volume of daily hassles, and were singled out as the predominant problems experienced in Germany.

- Acculturative stress increased with the duration of stay in Germany

- Family fragmentation, in general, and being separated from one's spouse, in particular, is one of the strongest predictor of acculturative stress

- Among all African migrants those who have come as 'economic refugees' are the ones worse off.

\section{Conclusion/Recommendations:}

The results of this study emphasize the importance of demographic variables and acculturative stress of African migrants in Germany. It is recommended that demand-tailored counselling be offered to Africans in Germany who are stressed, as stress is known to contribute to psychological and physical health problems among Africans (Idemudia, 2006). It is important that genuine attempts to support them are put in place. An unofficial attitude of "you should not be here in the first place" has a negative impact not only on the migrants, but also to the host country-Germany because of economic cost diverted to prison matters and repatriation costs, emergency medical care and administrative and police personnel. The welcomed immigrant is the cheaper immigrant! 
According to Chimanikire:

"It can be maintained that the best antidote to migration from the Third World and from Africa in particular is helping poor countries achieve more peaceful societies, freer and more democratic political systems, and higher economic growth. This would necessitate in many cases higher levels of aid and investment from the rich, industrial nations so alarmed by the influx of unwanted immigrants". (2002, p. 22)

To sum up, we may cautiously suppose that many of the challenges (trafficking and illegal routing, migrant rights and integration, education/information for citizens of receiving and sending countries) be carefully appraised and studies pursued in this direction as the world continues to globalize.

Acknowledgement: The study was made possible by Alexander von Humboldt Foundation, Germany.

\section{References}

ABRAMS, D. \& HOGG, M. A. (Eds.) (1990). Social identity theory: Constructive and critical advances. London: Harvester Wheatsheaf.

ADEPOJU, A (20II). Reflections on international migration and development in sub-Saharan Africa. African Population Studies, 25 (2), 298-318.

ATACA, B. (1996). 'Psychological and sociocultural adaptation of Turkish immigrants, Canadians and Turks,. Paper presented at the XIII Congress of International Association for Cross-cultural Psychology, Montreal, Canada.

BABIKER, I. E., COX, J. L. \& MILLER, P. (1980). 'The measurement of cultural distance and its relationship to medical consultation, symptomatology, and examination performance of overseas students at Edinburgh University'. Social Psychiatry, 15, 109-116.

BERRY, J. W. (1997). 'Immigration, acculturation and adaptation'. Applied Psychology and International Review, 46, 5-36.

BOCHNER, S. \& CAIRNS, L. G. (1976). 'An unobtrusive measure of helping behaviour toward aborigines'. In G.E. Kearney and d. W. McElwain (Eds) Aboriginal condition: Retrospect and prospect (pp. 344 - 356). Canberra: Australian Institute of Aboriginal Studies.

BYRNE, D. (1969). 'Attitudes and attraction'. In L. Berkowitz (Ed.), Advances in the experimental social psychology (Vol. 4, pp. 35-89). New York: academic Press.

CHIMANIKIRE, DONALD P. (2002). African migration: causes, consequences and future prospects and policy options. Paper presented for the UNU/WIDER conference on Poverty, International Migration and Asylum (September) Helsinki, Finland.

GERMAN FEDERAL OFFICE OF STATISTICS (2003). www.destatis.de Accessed 10th November, 2013.

FERNANDO, S. (1993). 'Racism and Xenophobia'. Innovation of Social Science Research, 6, 9-19.

FURNHAM, A. AND SHIEKH, S. (1993). 'Gender, generational and social support correlates of mental health in Asian immigrants'. International Journal of Social Psychiatry, 39, 22-33.

HOLBROOK, A, KROSNICK, J.A. \& PFENT, A.M. (2007). "Response rates in surveys by the news media and government contractor survey research firms". In J. lepkowski, N.C. Tucker, J.M. Brick, E.D. de Leeuw, L. Japec, P.J. Lavrakas, M.W. Link and R.L. Sangster (Eds). Advances in Telephone Survey Methodology (pp. 499-528), New York: Wiley.

IDEMUDIA, E.S. (2006). Global movement and health potential of black migrants in Germany: A study of mental health indices using MMPI. In TRANS. Internet-Zeitschrift fur Kulturwissenschaften. No.16/2005. WWW: http://www.inst.at/trans/I6Nr/08_3/idemudial6.h tm

IDEMUDIA, E.S. \& BOEHNKE K. (2005). Globalisierung, Afrika and afrikanische Immigranten in Deutschland: Ein empirischer Bericht. In A. Groh (eds) be-WEG-ung: Akademische Perspektiven auf Reisen und Ortswechsel, pP 49-69. Berlin: WEIDLER Buchverlag.

IDEMUDIA, E.S., \& BOEHNKE, K., (2006). An Assessment of African Migrants attitude in Germany: Implication for international migration, intercultural contact and globalization. African Psychopathologie, XXXII (I), 5-20.

IDEMUDIA, E.S. \& BOEHNKE, K. (20I0). I'm an alien in Deutschland: A quantitative mental health case study of African Immigrants in Germany (with an epilogue by John W. Berry). Frankfurt, Germany: PeterLang Publishers. ISSBN: 978-363I-59975-4). 
KATZ, D. \& BRALY, K. (1933). 'Racial stereotypes of one hundred college students'. Journal of abnormal and Social Psychology, 28, 280 - 290.

LIPPMAN, W. (1922). Public opinion. New York: Hartcourt \& Brace.

TAJFEL, H. (1970). Experiments in intergroup discrimination. Scientific American, 223, 92-102.

TAJFEL, H. (198I). Human groups and social categories. Cambridge, Cambridge University Press.

TANAKA, T., TAKAI, J., KOHYAMA, T. \& FUJIHARA, T. (1994). 'Adjustment patterns of international students in Japan'. International Journal of Intercultural Relations, 18, 55-75.

VEGA, W. A., GIL. A.G., WARHEIT, G.J., ZIMMERMAN, R. S. \& APOSPORI, E. (1993)
'Acculturation and delinquent behaviour among Cuban-American adolescents'. American Journal of Community Psychology, 21, II 3-125.

WARD, C., \& CHANG, W.C. (1994). Adaptation of American sojourners in Singapore. Raw unpublished data.

WARD, C., BOCHNER, S., \& FURNHAM, A. (200I). The Psychology of Culture Shock. (2nd Ed). London, GB: Routledge.

WARD, C. \& SEARLE, W. (1991). 'The Impact of value discrepancies and cultural identity on psychological and sociocultural adjustment of sojourners'. International Journal of Intercultural Relations, $\quad 15, \quad 209 \quad-\quad 225$. 